\title{
VISÃO COLABORATIVA APROXIMANDO STAKEHOLDERS PARA A CRIAÇÃO DE HABITAT DE INOVAÇÃO
}

Creusa Sayuri Tahara Amaral (c.sayuri.tahara @ gmai.com) - Universidade de Araraquara (UNIARA). Márcia Mazzeo Grande (mgrande @ fearp.usp.br) - Universidade de São Paulo (FEA-RP/USP). André Capaldo Amaral (acamaral@uniara.edu.br) - Universidade de Araraquara (UNIARA). Daniel Capaldo Amaral (amaral@ @sc.usp.br) - Universidade de São Paulo (EESC- USP).

\section{RESUMO}

A universidade vem sendo desafiada a incluir o empreendedorismo na formação dos pesquisadores, o que motivou o conceito de universidade empreendedora. Este desafio é especialmente importante para a área de biotecnologia no Brasil, dado o potencial de inovação. Há experiências relatadas em escritórios de inovação, ferramentas e métodos em desenvolvimento de novos produtos, mas como iniciar a transformação para consolidação de um habitat de inovação? O objetivo deste artigo é descrever uma experiência de uso da visão para a criação de um habitat de inovação e fomentar o empreendedorismo acadêmico, orientando iniciativas de empreendedorismo tecnológico entre alunos de graduação, pósgraduação, pesquisadores e professores. Além da contribuição no campo da teoria de universidade empreendedora, propõe o uso da visão como instrumento útil para a formação de habitat.

Palavras chave: Empreendedorismo; Universidade empreendedora; Habitat de inovação 


\section{INTRODUÇÃO}

O empreendedorismo é uma das formas de impulsionar a evolução da sociedade e uma importante engrenagem para o crescimento econômico. Promove a inovação, aumenta a produtividade, cria novos empregos e pode ajudar no enfrentamento dos desafios da sociedade quanto ao desenvolvimento sustentável, redução da pobreza e desigualdade social. Por esses motivos, diversos governos têm se empenhado em colocar em prática estruturas políticas e programas para promover o empreendedorismo.

O Global Entrepreneurship Monitor - GEM, iniciado em 1999, fruto de uma parceria entre a Babson College e a London Business School, desenvolve pesquisas sobre o papel do empreendedorismo no desenvolvimento social e econômico das nações. Atualmente, é a mais abrangente pesquisa anual sobre atividade empreendedora no mundo. GEM tem monitorado o empreendedorismo tanto em termos do estado da mentalidade empreendedora, motivações, atividades e ambição, quanto das condições estruturais dos países, necessárias para permitir que o empreendedorismo seja praticado na economia (BOSMA et al., 2020).

Desde o final dos anos 90 no Brasil, o empreendedorismo tecnológico vem sendo reconhecido como um assunto importante na política das instituições de ensino superior e há vários exemplos de programas de apoio ou incentivo, criados dentro de universidade, de forma a incorporar e proporcionar estas atividades. Costa e Torkomian (2008) descrevem, que as iniciativas de criação de spin offs acadêmicas no Brasil estão concentradas na região sudeste $(60 \%)$ e sul (24\%), sendo a USP, UNICAMP e UFSC as universidades com mais iniciativas.

Esta é uma nova e importante missão das universidades modernas (MUNIZ; PEREIRA, 2015), fruto de um processo de mudança que teve início ainda no século passado e que tem sido denominado de universidade empreendedora (ETZKOWITZ, 1998). A universidade empreendedora é aquela que além de ensinar e produzir pesquisa tem como meta ser também geradora de novos negócios - spin-offs, resultados das pesquisas (MUNIZ; PEREIRA, 2015).

A ideia de universidade empreendedora destaca o papel estratégico que laboratórios e centros de pesquisa desempenham, pelas suas habilidades de criar e difundir conhecimento, ampliando a capacidade inovativa da região na qual a universidade está instalada (NDONZUAU; PIRNAY; SURLEMONT, 2002).

Oliveira (2015) apresenta uma proposta de modelo para estímulo à criação de spin-offs acadêmicas, baseados em ecossistema de empreendedorismo. O modelo descreve elementos 
internos e externos à universidade que integram o ecossistema empreendedor, mas não detalha as ações a serem executadas e nem a estruturação de um processo de negócio.

Um dos desafios para o fomento ao empreendedorismo tecnológico, portanto, está na identificação de modelos, métodos e técnicas que permitam criar estruturas e organismos de apoio dentro das universidades, capazes de tornar eficiente o processo da formação empreendedora e com isso estimular a geração das spin-offs acadêmicas.

Esse desafio está sendo enfrentado por universidades de todo o mundo e é especialmente importante para a área de biotecnologia no Brasil, dado o seu potencial de inovação. Há muitas experiências de ações movidas por escritórios de inovação, ferramentas e métodos em desenvolvimento de novos produtos, mas não foram encontradas soluções para iniciar este processo atraindo stakeholders para um habitat próximo de universidades, visando fortalecer o ecossistema e caminhar no sentido de uma universidade-empreendedora. Seria possível utilizar uma visão para realizar o alinhamento entre potenciais parceiros que se deseja atrair para um Habitat de Inovação?

Assim, este artigo explora uma proposta de criação colaborativa de uma visão para um habitat de inovação para o empreendedorismo acadêmico. O artigo descreve uma experiência de uso da visão para a criação de um modelo de habitat de inovação, alinhando os diversos stakeholders do processo, alunos de graduação, pós-graduação, pesquisadores, professores, a instituição e empresas.

\section{O PROCESSO EMPREENDEDOR NO BRASIL}

Bosma et al. (2020), organizadores do GEM - Global Entrepreneurship Monitor, apresentam um estudo sobre a proporção de adultos que iniciam um novo negócio com tecnologias ou procedimentos que são novos em sua área, novos em seu país ou no mundo. Os resultados para o Brasil desse indicador é que o foco das iniciativas são para negócios novos na área.

De acordo com o estudo, as boas condições oferecidas pelo ambiente podem tornar muito mais fácil sustentar um novo empreendimento em um negócio já estabelecido, enquanto em condições difíceis pode ser mais fácil fechar o negócio e criar um novo empreendimento. A Suíça é classificada como a mais forte em termos de indicador de facilidade de iniciar e desenvolver um negócio, seguida de perto pela Holanda e Qatar. As pontuações mais baixas desse indicador são para Irã, Porto Rico e Paraguai (BOSMA et al.,2020). 
Os fatores que afetaram negativamente o empreendedorismo no Brasil incluem baixo crescimento econômico e turbulência política. Em 2019 viu-se importantes medidas que devem facilitar as iniciativas empreendedoras no Brasil como os projetos de reforma trabalhista, em vigor desde novembro de 2017, que permitiu maior flexibilidade aos contratos de trabalho, a Medida Provisória de Liberdade Econômica, que contempla políticas como a cessação de licenças para atividades de pequenos negócios de baixo risco, além da simplificação do sistema digital nacional de recolhimento de impostos e obrigações previdenciárias (BOSMA et al., 2020).

Na esfera financeira, a Lei Empresa Simples de Crédito - ESC (BRASIL, 2019) tem como meta aumentar o acesso ao financiamento para micro e pequenas empresas, e para o Micro Empreendedor Individual (MEI) visa formalizar o sistema de microfinanças. Outro programa de incentivo financeiro criado pelo governo é o Programa Nacional de Apoio às Microempresas e Empresas de Pequeno Porte - Pronampe (BRASIL b, 2021). Essa iniciativa, criada como medida de emergência durante a pandemia de 2020, passou a ser um programa permanente e proporciona crédito para pequenos negócios com juros atrativos, baseados na taxa Selic mais um teto de $6 \%$ ao ano.

O marco legal da Startup decretado pela Lei complementar 182/2021(BRASIL a, 2021) deve ser o novo vetor de desenvolvimento econômico, social e ambiental e institui regulações para o empreendedorismo inovador. Uma importante mudança prevista no Marco Legal das Startups é sobre o enquadramento de empresas como startups. Essa necessidade de considerar a startup como uma categoria de negócio faz com que se possa criar legislações especificas, sem comprometer outras empresas da economia. Outra mudança prevista no Marco Legal das Startups é sobre e novas regras tributárias que reduzirão custos, dando maior chance dessas empresas sobreviverem ao vale da morte das startups, até se consolidarem financeiramente para o crescimento.

\section{UNIVERSIDADE EMPREENDEDORA}

A universidade deve avaliar seu papel no processo de desenvolvimento socioeconômico da sociedade. Como um sistema evolutivo, a universidade adaptou-se em três correntes principais: a especialização, a diversificação e a hibridização. A especialização refere-se ao foco em educação. A diversificação surgiu mais recentemente, quando a universidade ampliou seu escopo, pela inclusão da pesquisa como função básica. O modelo híbrido, combina de 
modo integrado as diferentes funções estabelecidas durante o processo de diversificação (RODRIGUES; TONTINI, 1997).

A universidade é tão empreendedora e completa como universidade, quanto maior for seu grau de domínio técnico-científico e também quanto maior for sua capacidade de transmissão de seus conhecimentos à sociedade. $\mathrm{O}$ entendimento do conhecimento como um capital e o surgimento da "Universidade Empreendedora" são processos atuais no mundo, inclusive no Brasil (ARAUJO et al., 2005). Assim, a capacidade de adaptação a esse novo modelo absorvendo, aprendendo e estimulando o empreendedorismo será fundamental para as universidades nas próximas décadas

A universidade empreendedora deve estar inserida em um ecossistema favorável e ainda desenvolver um habitat de inovação que estabeleça todas as condições para que as oportunidades de inovação possam prosperar. De acordo com o RUE (Ranking de Universidade Empreendedora), indicador proposto pelo movimento Brasil Júnior, o estado de São Paulo tem 4 universidades entre as 10 melhores avaliadas, sendo a USP a primeira colocada no ranking de 2019 (BRASIL JÚNIOR, 2019).

\subsection{Habitats de Inovação}

A criação de ambientes que incentivem trocas de conhecimentos com metas inovadoras, por intermédio de parcerias entre universidades, empresas e governo são importantes no contexto de grande produção de informações e novas tecnologias. Os locais físicos onde ocorrem tais trocas são intitulados "habitats de inovação" (MACHADO; PEREIRA, 2019).

Os habitats de inovação definem um ambiente de integração da tripla hélice. São ambientes que oferecem estímulos ao desenvolvimento empreendedor em todas as fases do processo, desde o nascimento da ideia até a consolidação da empresa com foco em tecnologia e inovação. Os empreendedores buscam esses ambientes para estabelecer cooperações com universidades e centros de pesquisa, compartilhando o conhecimento e inovações (SILVA; SÁ; SPINOSA, 2019).

Os habitats de inovação são espaços de aprendizagem compartilhados com diversos atores (empresas, universidade, governo), onde a difusão do conhecimento tácito é intensificado, a interação entre empresas para o estabelecimento de parcerias tem maior incentivo, a interação das instituições de pesquisa e agentes governamentais para realização de pesquisas, que 
podem ser transferidas para o setor produtivo, contribuindo para o desenvolvimento econômico de uma cidade, região e do país (CORREIA; GOMES, 2010).

A convivência é o primeiro passo para a cooperação, um princípio reconhecido desde o trabalho pioneiro de Lee, Florida e Acs (2004), que demonstrou que a criação de novas empresas em uma determinada região está associada, entre outras variáveis, com a criatividade, diversidade, capital humano e crescimento populacional. Isso explica como uma cidade ou local que concentra estes fatores pode promover o empreendedorismo. Entretanto, o que se pode dizer quando a questão é incentivar a criação de um habitat de inovação em uma determinada área de conhecimento em quando há possíveis parceiros, não integrados. Baum, Calabrese e Silverman (2000) demonstraram que a capacidade das startups em estabelecer alianças, tem impacto direto na sua performance durante os primeiros estágios de desenvolvimento, e que está relacionada com a configuração apropriada da rede de parceiros, complementação de competências, bem como a capacidade de estabelecer um alinhamento entre rivais, para promover um ambiente de baixo risco.

Walrave et al. (2018), por meio de uma revisão ampla da literatura de ecossistema, encontraram proposições sobre o caminho de fortalecimento e criação destas complexas redes de stakeholders. Entre elas, os autores afirmam que é preciso estabelecer uma Proposta de Valor do Ecossistema (Value Proposition Ecosystem) e que esteja alinhada com um Modelo do Ecossistema (Model Ecosystem).

Combinando estes trabalhos, é possível reconhecer que, como premissa, o primeiro passo para o estabelecimento de habitats de inovação seria aproximar estes atores e promover o alinhamento, maximizando a complementariedade entre as competências e minimizando o risco de rivais.

\subsection{Conceito de Visão}

O fenômeno da formação de um entorno, em direção a um ecossistema de inovação, segundo a perspectiva proposta por Adner (2017), é essencialmente definido pelo alinhamento multilateral entre parceiros, permitindo que interajam para gerar uma proposta de valor que se materialize. Na literatura de gestão de operações, existe o construto "visão" muito relacionado a este alinhamento e que ajuda a compreender o fenômeno.

O construto visão foi primeiro introduzido em estudos sobre estratégia e equipes de projeto. Na gestão de operações, a "Visão" é utilizada nas áreas de Design Management, Project 
Management e New Product Development Process (BENASSI; AMARAL; FERREIRA JÚNIOR, 2016). Conforme Benassi, Amaral e Ferreira Junior (2016), o construto visão é uma representação gráfica ou textual do produto a ser desenvolvido.

Visão do produto, segundo Benassi (2009), é uma descrição gráfica sucinta de um produto, que ainda não existe, resultado de um projeto. A visão pode conter informações de forma, função, estados, módulos, requisitos e metas.

Assim, a visão do produto é definida como um conjunto de artefatos que descreve o resultado esperado de um projeto por meio de elementos visuais e textuais, os quais são elaborados de maneira concisa e colaborativa, em alinhamento com a estratégia que o projeto deve seguir, e que seja capaz de desafiar a equipe a alcançá-la (BENASSI; AMARAL; FERREIRA JÚNIOR, 2016). Existem vários métodos para se criar uma visão para uma equipe. Exemplos que permitem compreender melhor este artefato estão descritos no livro de Hekkert e Van Dijk (2001, 2011).

\section{METODOLOGIA}

Este artigo é um relato de um caso em que foi experimentada, de modo iniciante a proposta do uso do conceito de visão para a idealização de um habitat propício para a realização de parcerias e o desenvolvimento de inovação dentro do ambiente acadêmico.

A pesquisa descreve os passos para a criação de uma visão comum de um habitat de inovação na área de biotecnologia, com o intuito também de contribuir para consolidação dos atores da universidade empreendedora.

De forma geral, as etapas de pesquisa estão descritas a seguir:

1.Revisão da literatura. A primeira etapa do trabalho constituiu-se da revisão da literatura ampla, que envolveu temas que não estão detalhados neste artigo, como: governança de centros de inovação, habitats de inovação e núcleos de inovação tecnológica, open innovation em universidades;

2. Escolha do caso. O caso descrito neste artigo está associado a um projeto de pesquisa, que envolve os autores do trabalho. $\mathrm{O}$ caso refere-se à constituição do habitat de inovação em um programa de pós-graduação em biotecnologia de uma universidade privada do interior de São Paulo. O programa de pós-graduação tem 6 anos de existência e conta com 12 docentes/pesquisadores, desenvolvendo trabalhos 
associados à medicina regenerativa e química medicinal, com potencial de inovações. Este fato motivou a criação de um habitat de inovação;

3. Mapeamento de competências do corpo de pesquisadores do programa de pósgraduaçao. A partir de um formulário disponibilizado no google form, os pesquisadores descreveram seus principais projetos e palavras-chave. Foram realizadas reuniões com os pesquisadores para o alinhamento das competências do grupo;

4. Reuniões com parceiros empresariais. Foram realizadas reuniões com alguns stakeholders, para identificar potenciais de parcerias e mecanismo de aproximação. Nesta etapa, os pesquisadores apresentaram ao stakeholder, uma visão prévia do habitat de inovação, como referência do ambiente em que o projeto seria desenvolvido. O contato com as empresas não buscou avaliar o modelo, mas demonstrar uma estrutura favorável à parceria;

5. Proposta da primeira versão do modelo de habitat de inovação. A visão do habitat de inovação evoluiu, a medida que novas experiências dos autores do trabalho, e pela interação com outros contatos estabelecidos;

6. Apresentação do modelo aos potenciais parceiros do habitat de inovação. A proposta de visão do habitat de inovação foi apresentada a alguns representantes da instituição, como o coordenador do programa de pós-graduação em Biotecnologia e pesquisadores. Contudo, espera-se que todos os contatos com empresas, já iniciados possam ser continuados e a visão do habitat de inovação possa ser compartilhada com estes importantes parceiros do ecossistema de inovação.

\section{RESULTADOS}

As metas estratégicas do programa de pós-graduação, tratado neste estudo, deu inicio a um projeto de consolidação de um Centro de inovação, que está em andamento, cujo objetivo é constituir um habitat de inovação oportuno para o desenvolvimento de pesquisas aplicadas e inovações na área de Biotecnologia, em Medicina e Saúde. Busca-se assim, com o centro, constituir um ambiente atrativo para as indústrias do setor e proporcionar a interação entre os docentes/pesquisadores e discentes dos cursos de graduação e pós-graduação e outros centros de pesquisa e empresas, para realizar projetos inovadores de parceria. 
Considerando o contexto, o primeiro passo para concepção da visão do habitat de inovação para Centro de inovação foi o levantamento de competências dos pesquisadores do programa de pós-graduação. O levantamento foi realizado mediante o preenchimento de uma formulário, enviado a todos os pesquisadores, via google form. A partir das respostas foi elaborado uma síntese com as competências relatadas, que foram refinadas em várias reuniões, até a identificação de um consenso sobre como descrever as competências em pesquisas do programa de pós-graduação.

O mapa de competências foi o primeiro elemento para a implementação de estratégias para busca de parceiros para o desenvolvimento de projetos inovadores. Foram realizadas reuniões com empresas, informais e portanto não seguiram roteiro ou protocolo com coleta de dados, mas apenas buscando demandas alinhadas às competências dos pesquisadores do programa. Indiretamente foram identificados elementos necessários para o desenvolvimento de confiança entre as partes, como a sinergia de propósitos.

A figura 1 ilustra o resultado dessas interações. Ela representa uma visão do habitat de inovação, dentro do ambiente da universidade. O ambiente recebe influências da cultura institucional da universidade e de sua estratégia. O habitat de inovação segue as diretrizes da política de inovação da instituição como principal referência para o estabelecimento dos contratos de parceria e para as iniciativas empreendedoras, como a constituição de spin-offs e empresas juniores. Um destaque deve ser dado à presença da empresa junior na visão concebida do habitat de inovação, pois inclui no ambiente um importante ator do processo de incentivo ao empreendedorismo, que é o aluno de graduação. Para a instituição em questão, a constituição de empresa junior é um desafio, que está nas fases iniciais de criação.

Outros atores participam do habitat como: grupos de pesquisa, laboratórios, NIT, fundação de apoio, pesquisadores, pós-graduação, graduação, empresa júnior, empresas, spin-offs, startups e ICTs. Estes grupos devem estabelecer parcerias para o desenvolvimento de projetos em diversos níveis de maturidade, apoiados pela infraestrutura do habitat de inovação e contribuindo para a consolidação e evolução da cultura empreendedora. $O$ habitat deve estabelecer um sistema de governança para que se consolide um ambiente saudável de colaboração.

Neste habitat de inovação, os projetos podem ser desenvolvidos, nos diversos níveis de maturidade tecnológica (TRL- Technology Readiness Levels) com o envolvimento de 
diferentes atores, seguindo um modelo de desenvolvimento de tecnologia ou de desenvolvimento de produtos/serviços.

A visão do habitat de inovação deverá colaborar com o entendimento dos pesquisadores vinculados ao programa sobre a importância de buscarem novas parcerias e colaborações, consolidando os propósitos de inovação que devem ser perseguidos.

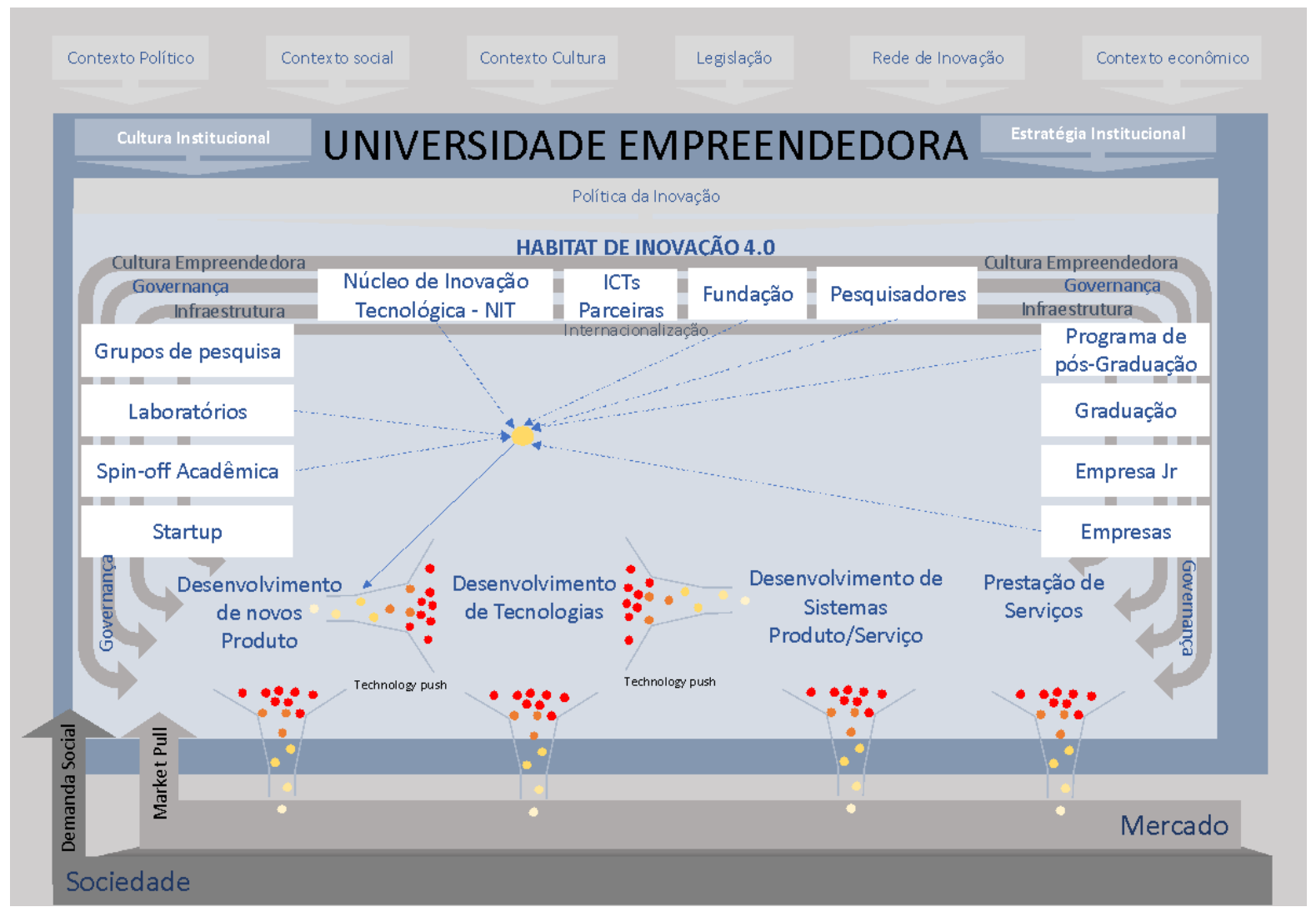

FIGURA 1: Habitat de inovação 4.0. Fonte: Elaborada pelos autores

\section{DISCUSSÃO E CONCLUSÃO}

O desenvolvimento de um modelo para o empreendedorismo acadêmico, tal como o proposto neste artigo em conjunto com a lei complementar 182/2021, o marco legal das startups, podem contribuir para que sejam consolidados os ambientes de inovação e a universidade aprimore o papel de agente promotor do empreendedorismo tecnológico.

O habitat de inovação e a ideia de uma visão construída de forma coletiva por atores potenciais, para a criação de um habitat de inovação é uma proposta que pode ser replicada, o que ajudaria a validar a atuação de agentes de inovação e profissionais das esferas 
governamentais, gestão acadêmica envolvidos em iniciativas de universidades empreendedoras.

O modelo do habitat de inovação resultante está servindo como um guia, para que os diversos atores do processo sejam motivados e capacitados para a geração de novos negócios ( spin-offs acadêmicos), promovendo o alinhamento dos parceiros, com vistas a potencializar a cooperação.

A proposta de visão do habitat de inovação apresentada neste artigo deve ser continuada para agregar ajustes e novos detalhamentos. Espera-se compartilhar a proposta com todos os colaboradores do programa, por meio de reuniões dirigidas, workshops, de modo que novas ideias possam surgir para aprimorar e tornar consistente o conceito de habit de inovação para o programa de pós-graduação e também para a instituição. Espera-se também apurar como serão os desdobramentos na forma de projetos e a própria consolidação do centro de inovação no programa de pós-graduação.

\section{AGRADECIMENTOS}

A pesquisa teve apoio da FUNADESP, por meio de bolsa pesquisador.

\section{REFERÊNCIAS}

ADNER, R. Ecosystem as structure: An actionable construct for strategy. Journal of Management, v. 43, n. 1, p. 39-58, 2017.

ARAÚJO, M. H. et al. "Spin-off" acadêmico: criando riquezas a partir de conhecimento e pesquisa. Quim. Nova, v. 28, Suplemento, S26-S35, 2005.

BAUM, J. A.C.; CALABRESE, T.; SILVERMAN, B. S. Don't go it alone: alliance network composition and startups' performance in Canadian biotechnology. Strategic Management Journal, v. 21, n. 3, p. 267-294, 2000

BENASSI, J. L. G. Avaliação de modelos e proposta de método para representação da visão do produto na gestão ágil de projetos. Dissertação (Mestrado) - Escola de Engenharia de São Carlos, Universidade de São Paulo, 2009.

BENASSI, J. L. G.; AMARAL, D. C.; FERREIRA JUNIOR, L. D. Towards a conceptual framework for product vision. International journal of Operations \& Production Management, v. 36, n. 2, p. 200-219, 2016.

BOSMA, N. et al. Global entrepreneurship monitor 2019/2020 global report. [SI]: Global Entrepreneurship Research Association (GERA), 2020.

BRASIL a. Lei complementar $n^{\circ} 182$, de $1^{\circ}$ de junho de 2021, institui o marco legal das startups e do empreendedorismo inovador. Disponível em: https://www.in.gov.br/en/web/dou/-/lei-complementar-n-182-de-1de-junho-de-2021-323558527. Acesso em: 13/07/2021. 
BRASIL b. Lei $\mathrm{n}^{\circ}$ 14.161, 02 de junho de 2021, permite o uso do Programa Nacional de Apoio às Microempresas e Empresas de Pequeno Porte - PRONAMPE. Disponível em: https://www.in.gov.br/en/web/dou/-/lei-n-14.161-de-2-de-junho-de-2021-323831470. Acesso em: 13/07/2021.

BRASIL. Lei complementar $n^{\circ}$ 167, a empresa simples de crédito, sancionada no dia 24 de abril, de 2019. Disponível em: http://www.planalto.gov.br/ccivil_03/LEIS/LCP/Lcp167.htm. Acesso em 13/07/2021.

BRASIL JÚNIOR. Ranking de Universidade Empreendedora 2019, Confederação Brasileira de Empresas Juniores, 2019.

CORREIA, A. M. M.; GOMES, M. L. B., Habitat de inovação PAQTCPB: identificando ações de sucesso, Revista Gestão e Sociedade CEPEAD/UFMG, v. 4, n. 8, 2010.

COSTA, L. B.; TORKOMIAN, A. L. V.. Um Estudo exploratório sobre um novo tipo de empreendimento: os spin-offs acadêmicos, RAC, Curitiba, v. 12, n. 2, p. 395-427, Abr./Jun. 2008.

ETZKOWITZ, H. From zero-sum to value-added strategies: the emergence of "knowledge-based industrial policy in the states of the United States." Policy Studies Journal, v. 25, n. 3, p. 412-424, Sept.1998.

HEKKERT, P.; VAN DIJK, M.. Designing from context: foundations and applications of the ViP approach. In: Lloyd, P.; Christiaans, H. (ed.). Designing in context: Proceedings of design thinking research symposium 5. Amsterdam: Delft University Press, 2001.

HEKKERT, P.; VAN DIJK, M.. Vision in product design: handbook for innovators. Amsterdam: BIS, 2011.

LEE, S. Y.; FLORIDA, R.; ACS, Z. Creativity and entrepreneurship: a regional analysis of new firm formation. Regional Studies, v. 38, n. 8, p. 879-891, 2004.

MACHADO, A. B.; PEREIRA, L. C. Habitat de inovação: conceitos e importância, EcoDebate, 2019. Disponível em: https://www.ecodebate.com.br/2019/03/14/habitat-de-inovacao-conceitos-e-importancia-porandreia-de-bem-machado-e-lauro-charlet-pereira.

MUNIZ R.M.; PEREIRA L.B. Universidade empreendedora: um conceito ex ant no caso de uma universidade brasileira. In: V Coloq Int sobre Gestión Univ en América del Sur., p.1-18, 2015.

NDONZUAU, F. N.; PIRNAY, F.; SURLEMONT, B. A Stage model of academic spinoff creation. Technovation, v. 22. p.281-289, 2002.

OLIVEIRA, M. R. Modelo para o estímulo à criação de pin-offs acadêmicas baseado em ecossistemas empreendedores, Tese (Doutorado), UFSCar, São Carlo, 2015.

RODRIGUES, L.C.; TONTINI, G. A universidade empreendedora: geração e transferência de tecnologia como fator agregador. Revista de Negócios, v.2, n4, p. 37-49, 1997.

SILVA, M. V. G. ; SÁ, D.; SPINOSA, L. M. Ecossistemas de inovação: proposta de um modelo de governança para o exército brasileiro. Revista Brasileira de Gestão e Inovação, v.6, n.3, Mai/Ago, 2019.

WALRAVE, B. et al. A multi-level perspective on innovation ecosystems for path-breaking innovation. Technological Forecasting and Social Change, v. 136, p. 103-113, 2018. 